\title{
Chico Antonio n' A Barca \\ Mário de Andrade e outros diálogos com a tradição musical popular
}

\author{
Lincoln Antonio ${ }^{1}$
}

\section{A Barca e Mário de Andrade}

O trabalho d' A Barca, coletivo musical de São Paulo, começou em 1998 a partir do diálogo com a experiência de Mário de Andrade como viajante etnográfico ${ }^{2}$. O estudo do material musical recolhido pelo escritor aliado à experiência em campo do grupo resultou na recriação de diversas peças musicais da tradição popular ${ }^{3}$. Enquanto Mário de Andrade anotou músicas de São Paulo, Alagoas, Pernambuco, Paraíba e Rio Grande do Norte, A Barca realizou gravações de campo e estabeleceu diálogos com mestres e grupos do Pará, Maranhão, Ceará, Paraíba, Pernambuco, Alagoas, Bahia, Minas Gerais e São Paulo ${ }^{4}$ Todo o material registrado pel' A Barca foi copiado e devolvido a cada grupo ou mestre, e grande parte dele foi editado em CDs e em DVDs documentários ${ }^{5}$.

Embora não gostasse de viajar, como conta em seu diário de viagem que chamou de $O$ turista aprendi $z^{6}$, Mário de Andrade realizou

1 Compositor, pianista, arranjador e produtor musical. Bacharel em Música - Composição e regência pela Universidade Estadual Paulista “Júlio de Mesquita Filho" (Unesp, São Paulo, SP, Brasil). E-mail: lincoln@barca.com.br

2 Em sua fase inicial, A Barca era composta por Lincoln Antonio, Renata Amaral, Sandra Ximenez, Juçara Marçal, Marcelo Pretto, Chico Saraiva, Thomar Rohrer, Ligeirinho, Beto Teixeira, Aguinaldo Pereira e Mauricio Alves.

3 A BARCA. CD Turista aprendiz. São Paulo: CPC-Umes, 2ooo. CASA FANTI ASHANTI \& A BARCA. CD Baião de princesas. São Paulo: CPC-Umes, 2oor. A BARCA. CD Trilha. São Paulo, Cooperativa de Música, 2006.

4. O acervo integral de gravações em áudio d' A Barca pode ser consultado na internet no endereço http://www.acervobarca.com.br. Este acervo recebeu, em 2011, o Prêmio Rodrigo Mello Franco, concedido pelo IPHAN, na categoria Promoção e Comunicação.

5 A BARCA. Trilha, toada e trupé (3 CDs e um DVD documentário em longa-metragem). São Paulo: Independente, 2006. Coleção Turista aprendiz (7 CDs e um DVD com 7 documentários em curta metragem). São Paulo, Independente, 2007.

6 ANDRADE, Mário de. O turista aprendiz. Estabelecimento de texto, introdução e notas de Telê Porto Ancona Lopez. São Paulo: Duas Cidades/ Secretaria da Cultura, Ciência e Tecnologia, 1976. 
ao menos três viagens importantes: às cidades históricas de Minas Gerais em 1924; "ao Amazonas até o Peru, pelo Madeira até a Bolívia e por Marajó até dizer chega" em 1927; e ao Nordeste, viagem etnográfica realizada em 1928-29. Nessa última ocasião, anotou centenas de peças de manifestações populares como maracatu, coco, chegança, congos, boi e cantos de trabalho. Em diversos momentos de sua vida, Mário de Andrade retornou a esse material com a intenção de organizá-lo num grande compêndio. Não conseguiu levar a cabo este projeto, e a maior parte do material foi editado após sua morte por Oneyda Alvarenga, sua aluna e colaboradora ${ }^{7}$. Em vida, publicou obras importantes que trazem registros musicais, como Ensaio sobre a música brasileira e Aspectos da música brasileira ${ }^{8}$.

O livro Os cocos, editado por Oneyda Alvarenga, reúne 245 peças, quase todas anotadas por Mário de Andrade na viagem ao Nordeste. Esse livro foi a principal fonte de estudo e exercício criativo para A Barca e nele sobressai a figura de um cantador: Chico Antonio.

7 Os livros de Mário de Andrade organizados por Oneyda Alvarenga e trabalhados pel' A Barca são:

a) Danças dramáticas brasileiras - $I^{\circ}$ tomo. Belo Horizonte: Itatiaia, 1982. Reúne 95 documentos musicais das cheganças (RN, PB, PE) e 17 do pastoril (PE), além de estudos, textos e anexos;

b) Danças dramáticas brasileiras - $2^{\circ}$ tomo. Belo Horizonte: Itatiaia, 1982. Reúne 64 documentos músicas dos congos (RN, PB), zo de maracatu (PE) e 15 de caboclinho (RN, PB), além de estudos, textos e anexos;

c) Danças dramáticas brasileiras - $3^{\circ}$ tomo. Belo Horizonte: Ed. Itatiaia, 1982. Reúne 110 documentos musicais do bumba-meu-boi (RN, PE, CE, AM, PA, RJ), e 53 de congadas e moçambiques (SP), além de textos e anexos;

d) Música de feitiçaria do Brasil. Belo Horizonte: Itatiaia, 198z. Reúne 49 documentos musicais sobre o assunto, além de estudos, textos e anexos;

e) Os cocos. São Paulo: Livraria Duas Cidades, 1984. Reúne 245 documentos musicais, além de estudos, textos e anexos;

f) Melodias do boi e outras peças. São Paulo: Livraria Duas Cidades, 1987. Reúne 248 documentos musicais diversos, textos e anexos.

8 ANDRADE, Mario de. Ensaio sobre a música brasileira. São Paulo: Livraria Martins Editora, 1962. Reúne, além do ensaio do título (1928), 120 documentos musicais diversos e o estudo "A música e a canção populares no Brasil" (1936) . $A s$ pectos da música brasileira. São Paulo: Livraria Martins Editora, 1965. Reúne os estudos "Evolução social da música no Brasil" (1941), "Os compositores e a língua nacional" (1938), "A pronúncia cantada e o problema do nasal através dos discos", “O samba rural paulista" (1941) e "Cultura musical" (1935). 
Estou divinizado por uma das comoções mais formidáveis da minha vida. Chico Antonio apesar de orgulhoso:

\author{
"Ai, Chico Antonio \\ Quando canta \\ Istremece \\ Esse lugá!..."
}

Não sabe que vale uma dúzia de Carusos. Vem da terra, canta por cantar, por uma cachaça, por coisa nenhuma e passa uma noite cantando sem parada. Já são 23 horas e desde às 19 que canta. Os cocos se sucedem tirados pela voz firme dele. ${ }^{9}$

Mário de Andrade conheceu Chico Antonio no Rio Grande do Norte e anotou por volta de 50 cocos "tirados" por ele. E descreveu o encontro com o cantador em várias crônicas entusiasmadas, conforme se lê na edição de $O$ turista aprendiz elaborada por Telê Porto Ancona Lopez.

Que artista. A voz dele é quente e duma simpatia incomparável. A respiração é tão longa que mesmo depois da embolada inda Chico Antonio sustenta a nota final enquanto o coro entra no refrão. $\mathrm{O}$ que faz com o ritmo não se diz! Enquanto os três ganzás, único acompanhamento instrumental que aprecia, se movem interminavelmente no compasso unário, na "pancada do ganzá”, Chico Antonio vai fraseando com uma força inventiva incomparável, tais sutilezas certas feitas que a notação erudita nem pense em grafar, se estrepa. E quando tomado pela exaltação musical, o que canta em pleno sonho, não se sabe mais se é música, se é esporte, se é heroísmo. Não se perde uma palavra que nem faz pouco, ajoelhado pro "Boi Tungão", ganzá parado, gesticulando com as mãos doiradas, bem magras, contando a briga que teve com o diabo no inferno, numa embolada sem refrão, durada por 10 minutos sem parar. Sem parar. Olhos lindos, relumeando numa luz que não era do mundo mais. Não era desse mundo mais. ${ }^{10}$

O coco, nas suas várias formas, é ainda hoje muito vivo no Nordeste brasileiro. Uma das formas é o coco de roda, quando os dançadores/coro se colocam em roda respondendo ao cantador num refrão simples. Outra

9 ANDRADE, Mario de. O turista aprendiz, p. 273.

10 ANDRADE, Mario de. O turista aprendiz, p. 277. 
forma é o coco de embolar, quando o cantador, também chamado de coqueiro, improvisa versos numa segunda parte melódica, alternando com o refrão cantado pelo coro. Em ambas as formas, o coco pode ser considerado como uma proto-canção, já que não chega ao acabamento da canção popular, constituindo-se como "obra aberta", sobretudo quando a improvisação é seu elemento central. Dessa maneira, cada performance de um coco é uma obra única, tanto maior seja o talento do cantador como improvisador. Em 2005, A Barca registrou a manifestação através do trabalho de cantadores como Mestre Verdelinho (Alagoas), Biu Roque (Pernambuco), Odete do Pilar (Paraíba) e das cantadeiras do quilombo de Caiana dos Crioulos (Paraíba).

Mas o primeiro cantador que A Barca conheceu, em 1998, foi Chico Antonio, através dos livros de Mário de Andrade.

Bom Jardim, 11 de janeiro - Passei hoje o dia com Chico Antonio, conversando, grafando algumas das melodias que ele canta. Agora ele está de novo giragirando no coco e vou dedicar mais esta crônica a ele. Principiou a cantar faz pouco e até onde o vento leva a toada, os homens do povo vem chegando, mulheres, vultos quietos na escureza, sentam no chão, se encostam nas colunas do alpendre e escutam sem cansar. A encantação do coqueiro é um fato e o prestígio na zona, imenso. Se cantar a noite inteira, noite inteira os trabalhadores ficam assim, circo de gente sentada, acocorada em torno de Chico Antonio uirapuru, sem poder partir. ${ }^{11}$

11 ANDRADE, Mario de. O turista aprendiz, p. 277. 


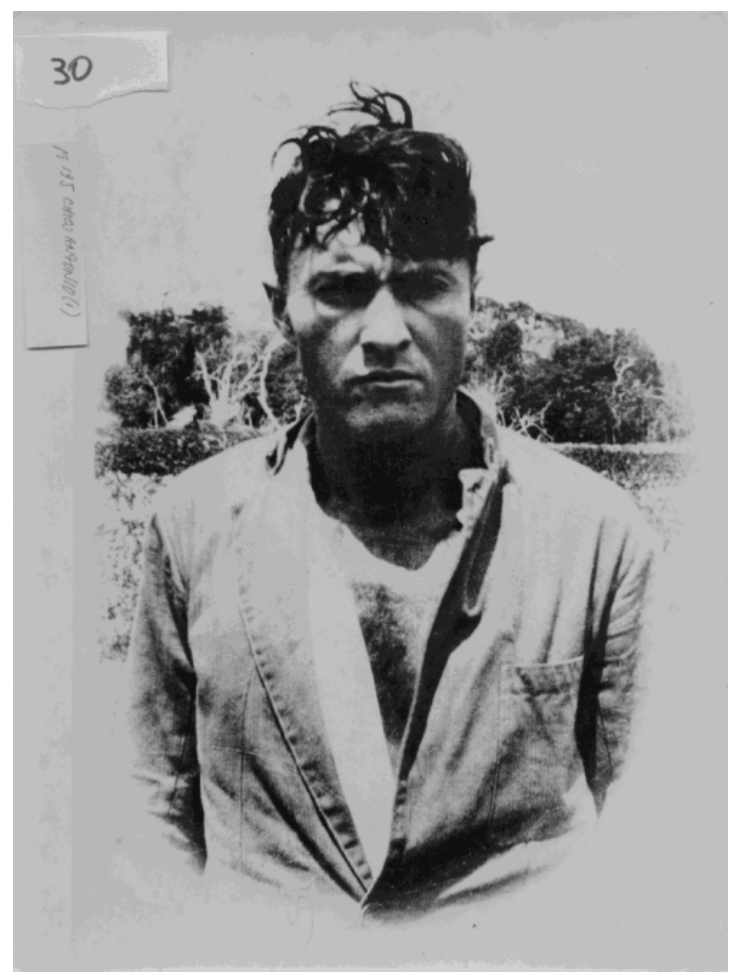

Figura 1: Chico Antonio, foto de Mário de Andrade. Arquivo do Instituto de Estudos Brasileiros da USP - Fundo Mário de Andrade, código do documento: MA-F-0994

No encarte de seu primeiro CD, Turista aprendiz, lançado em 2000, A Barca escreveu:

Na aula "O artista e o artesão" (in O Baile das Quatro Artes), Mário de Andrade discute a importância do artesanato como parte da técnica artística que se pode ensinar, que é necessária para movimentar o material, pra que a obra de arte se faça. Técnica demais, porém, pode descambar para uma virtuosidade perigosa, vazia, ou para um formalismo excessivo, distanciando a obra de sua função social. É preciso que haja "um justo equilíbrio entre a arte e o social, entre o artista e a sociedade". Portanto, é necessário que o artista adquira "uma severa consciência artística que o moralize", envolvendo-se com os problemas imediatos do seu tempo. Essa dimensão social da arte não se localiza fora dela, mas no próprio fazer artístico. 
O trabalho da Barca começa do aprendizado e movimentação de um material específico: a música vinda das tradições populares de todo o Brasil. São melodias, ritmos, vozes, timbres e versos de artistas anônimos, como finas camadas de areia que vão se sobrepondo ao longo do tempo. Sempre em transformação, a arte popular é genuinamente social, porque funcional, seja no sentido lúdico ou religioso. Ela precisa interessar, sempre. Na sua origem está a busca da comunicação entre os homens.

Baseado nesse desejo de comunicação, nos lançamos a essa tarefa nada simples de pesquisar, estudar e apresentar esse material, sempre atentos às suas características e exigências, porque "se o espírito não tem limites na criação, a matéria o limita na criatura". Em janeiro de 1999 a Barca viajou por cidades do interior do Pará e do Maranhão mostrando essa experiência e conhecendo muitas outras coisas que acabaram influenciando nosso trabalho e entrando para o repertório do grupo. Essa viagem, marcada pela vontade mútua de compartilhar experiências, nos deu uma visão muito clara do quanto a música brasileira é ao mesmo tempo múltipla e integradora. Tocando e cantando, a gente se entende. ${ }^{12}$

A Barca recriou vários cocos anotados por Mário de Andrade. Falaremos aqui de três deles: "Justino Grande", "ÊE Tum" e "Manué". Cada um deles com características formais próprias que resultaram em processos distintos de edição e arranjo.

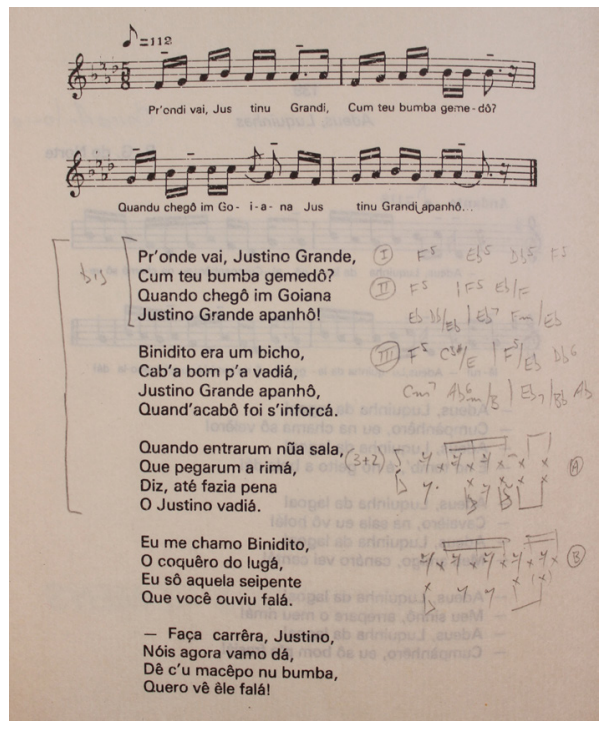

12 A BARCA. CD Turista aprendiz. São Paulo, CPC-Umes, 2000. 


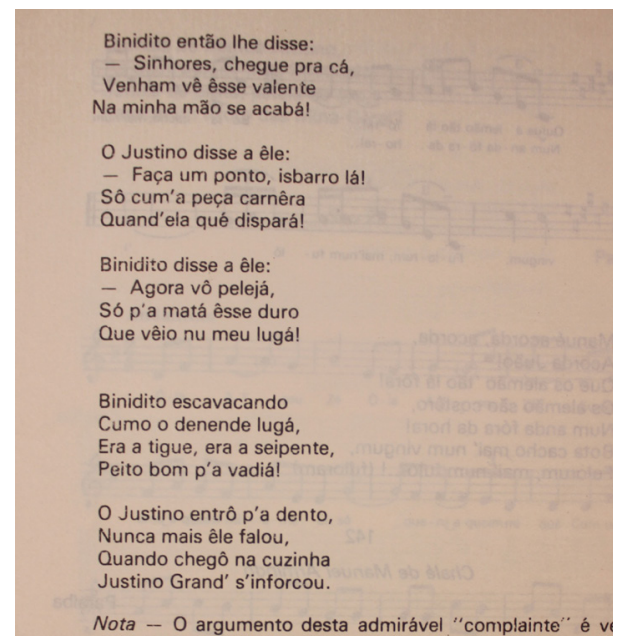

\section{Justino Grande, um coco em cinco tempos}

Figura 2: Páginas 196 e 197 do livro Os cocos, anotações de Lincoln Antonio feitas durante o trabalho d' A Barca.

“Justino Grande" é um surpreendente coco em compasso quinário. A célula básica do coco é invariavelmente em compasso binário, descrevendo tanto a base rítmica da percussão, quanto o passo da dança.

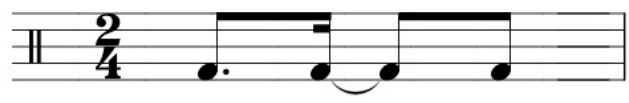

Figura 3: Célula rítmica básica do coco.

No caso de "Justino Grande", a melodia desenvolve-se num compasso de cinco tempos. Se subdividimos o compasso $2 / 4$ e consideramos a célula básica do coco em compasso 4/8, essa célula ganhará mais uma colcheia no compasso $5 / 8$.

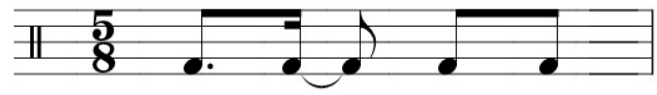

Figura 4: Célula rítmica básica de "Justino Grande”. 
A letra de "Justino Grande" é um raro caso pois - em vez de improvisar sobre um ou vários assuntos, geralmente descolados do refrão - conta uma história, aproximando-se assim da canção popular. Canta-se a "peleja" entre dois coqueiros, Justino Grande e Benedito, culminando com a derrota do primeiro. Outra singularidade é a cadência harmônica ocorrer no meio do compasso ou, mais precisamente, no quarto pulso.

$$
\begin{array}{lllllllllllllllllllllll}
\mathrm{Fm} & & & \multicolumn{1}{c}{\mid \mathrm{Fm}} & \multicolumn{4}{c}{\mathrm{Eb}} & \mid \mathrm{Eb} & & \mathrm{Db} & \mid \mathrm{Db} & \mathrm{Eb} & \mathrm{Fm} & \| \\
1 & 2 & 3 & 4 & 5 & 1 & 2 & 3 & 4 & 5 & 1 & 2 & 3 & 4 & 5 & 1 & 2 & 3 & 4 & 5
\end{array}
$$

A profusão de versos encontrados no livro Os cocos, a variedade de temas e de diálogos, levou A Barca a experimentar novas edições e arranjos das peças, sobretudo pelo gênero constituir-se como "obra aberta", refrão que recebe versos improvisados na segunda parte.

\section{Ê Tum: duelo de emboladas}

Mário de Andrade já havia publicado o refrão de “Ê Tum” em seu Ensaio sobre a música brasileira ${ }^{13}$, provavelmente tendo-o recebido de algum colaborador. Mas é de Chico Antonio a versão que está n'Os cocos, a qual, além do refrão, apresenta ainda uma segunda parte.

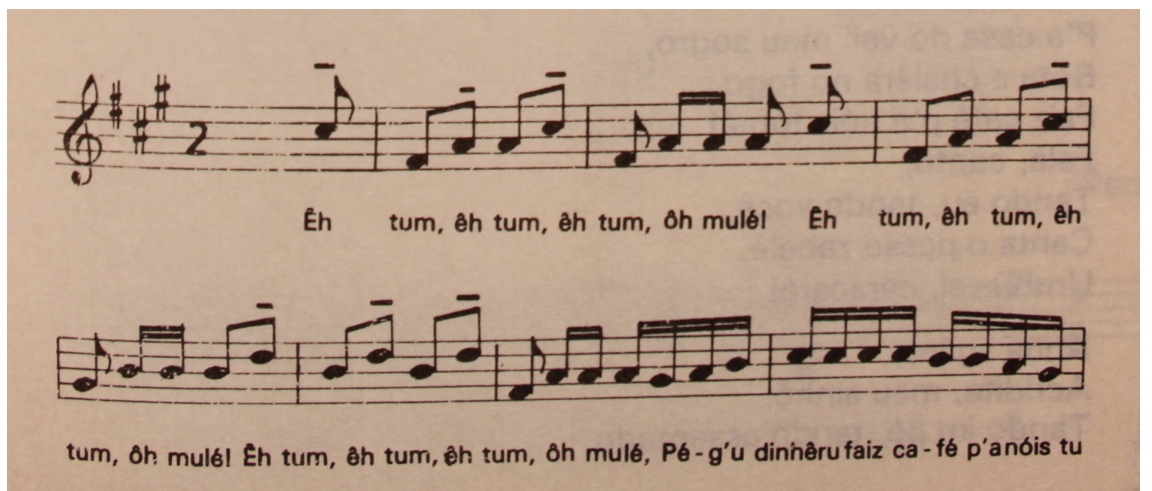

13 ANDRADE, Mario de. Ensaio sobre a música brasileira, p. 125. 


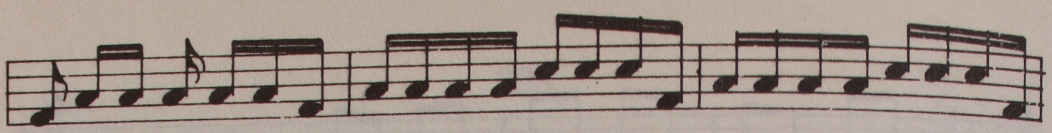

má, ôh mu-|él Anda li- gê-rư A minha regr'é di co-quêru, Istrèmeci u mund'in

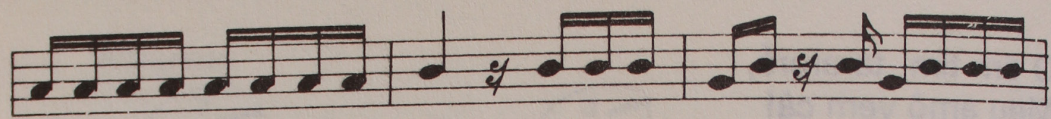

tê-ru, Trupe-lăo, rí-u, ca ná; Tandu zan-gadu Ba-ianu a galo-

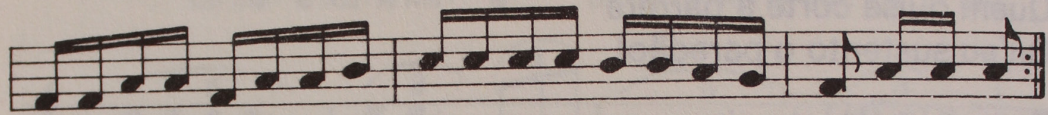

padu, Naque-li dia mai- cadu Fui a- prendê a na dá óh mu lé!

Figura 5: Páginas 289 e 290 do livro Os cocos, base para o trabalho do grupo A Barca.

$\mathrm{Na}$ segunda parte, o cantador improvisa quadras seguindo uma forma comum nos cocos anotados por Mário de Andrade: estrofes duplas de quatro versos, tendo o primeiro verso de cada estrofe quatro sílabas poéticas e os restantes, sete.

Anda ligero,

A minha regra é de coquero, ${ }^{14}$

Istremece o mundo intero,

Trupelão, rio, caná;

Tando zangado,

Baiano agalopado,

Naquele dia maicado,

Fui aprendê a nadá!

A versão d' A Barca para o coco "Ê Tum" de Chico Antonio, gravada no disco Turista aprendiz, fez um embate de dois cantadores na segunda parte, alternando estrofes entre eles, como acontece na cena cantada no coco "Justino Grande". Esses versos vieram de outros cocos de Chico

14 Conforme a partitura, o "A" que inicia o segundo verso é cantado junto com a sílaba final, átona, de "ligeiro", do primeiro verso. 
Antonio, mas também vieram de outros cantadores anotados por Mário de Andrade.

(Juçara Marçal)

corre, menina

pra casa do véio, meu sogro

bote a chalera no fogo

faiz café pra nóis tumá

(Sandra Ximenez)

corre, menina

na casa do funileiro

chegue lá, pergunte a ele

por quanto faiz um ganzá

(Marcelo Pretto, Juçara Marçal e Sandra Ximenez - refrão)

(Juçara Marçal)

fala, coquero

da cabeça de cumbuca

você hoje se amaluca

na pancada do ganzá

fala, coquero

da barriga de monturo

você fala no escuro

porque meu talento dá

(Sandra Ximenez)

olha, coquero

na bolada americana

si o esp'rito num m'ingana

eu também sei embolá

bolada num

bolada num, bolada notro

atirei com bola solta

num jogo de rebolá

(Juçara Marçal)

tome cuidado

diz, é poco mais o meno

minha bola tem veneno

quando eu pego no ganzá 
eu dei um tombo

quatro tombo no martelo

eu sô feito no duelo

rimeiro, vamo rimá

(Marcelo Pretto, Juçara Marçal e Sandra Ximenez - refrão)

(Sandra Ximenez)

passe pr'aqui

passe pr'ali, passe p'o canto

que eu daqui num me alevanto

quantas tapa qué levá?

ande ligero

arrepare, cavalero

eu sô um bicho ligero

na pancada do ganzá

(Juçara Marçal)

ande ligero

arrepare, meu sinhô

tando em pé, tando assentado

eu sei dá pulo mortá

ande ligero

no martelo agalopado

abr'u olho, camarada

veja o jeito d'eu bolá

(Sandra Ximenez)

caba danado

cabo da bola malina

você memo é que m'insina

lavá ropa sem moiá

é tranca, é bola

é tranca, é bola, é parafuso

a baleia deu um urro

do out'o lado do má

(Marcelo Pretto, Juçara Marçal e Sandra Ximenez - refrão)

(Juçara Marçal)

embola a lua

embola o sol, embola o vento 
meto a cabeça, vô dento

qu'eu também vô guerriá

faca de ponta

é danada pra custela

nego vendo a ponta dela

morre doido, num vai lá

(Sandra Ximenez)

poeta novo

num monta no meu cangote

se montá leva chicote

morre doido de apanhá

passe pr'aqui

passe pr'ali seu gororoba

que você engole cobra

com farinha de imbuá

(Juçara Marçal)

no meu cercado

cabrito novo num berra

nuvíu de pé de serra

num briga com malabá

caba valente

num me diga desaforo

quem num pode com besoro

num assanha mangangá

\section{(...)}

(Juçara Marçal, Sandra Ximenez e Marcelo Pretto)

ande ligeiro

a minha regra é de coqueiro

estremece o mundo inteiro

trupelão, rio, caná

eu sou coqueiro

eu sou bicho cantadô

inda que você num queira

eu seria, eu era, eu sô

Voltando a Mário de Andrade: 
Porque Chico Antonio não é só a voz maravilhosa e a arte esplêndida de cantar: é um coqueiro muito original na gesticulação e no processo de tirar um coco. Não canta nunca sentado e não gosta de cantar parado. Forma os respondedores, dois, três, em fila, se coloca em último lugar e uma ronda principia entontecedora, apertada, sempre a mesma. Além dessa ronda, inda Chico Antonio vai girando sobre si mesmo. Ele procura de fato ficar tonto porque, quanto mais gira e mais tonto, mais o verso da embolada fica sobrerrealista, um sonho luminoso de frases, de palavras soltas, em dicção magnífica. Poemas que nenhum Aragon já fez tão vivo, tão convincente e maluco. É prodigioso. ${ }^{15}$

\section{Manué: misturando versos e melodias}

Em "Manué", A Barca experimentou um arranjo mais complexo, envolvendo duas peças distintas. A primeira é uma toada do boi-bumbá Pae do Campo, gravada pela Missão de Pesquisas Folclóricas em 1938, em Belém do Pará ${ }^{16}$.
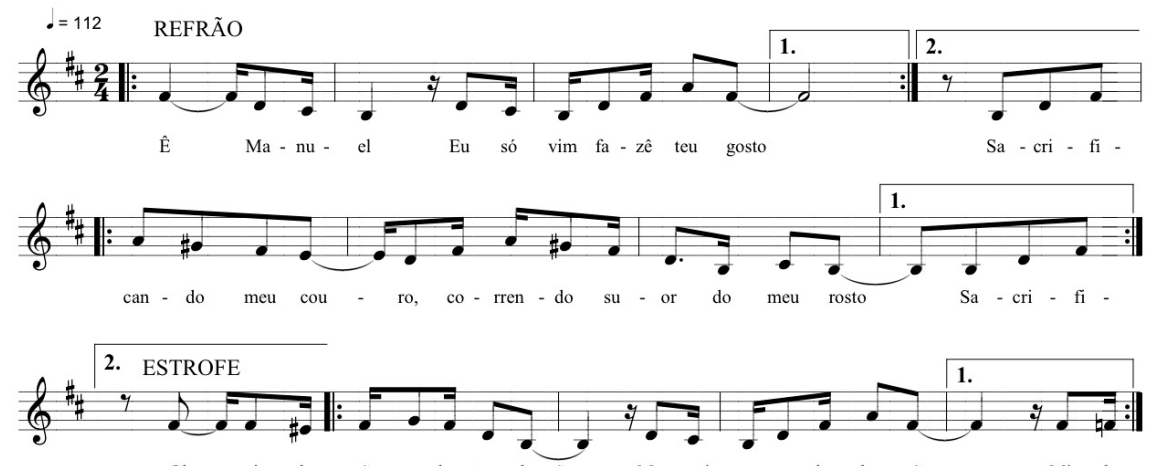

Oh, mi - nha mãe me bo - tea benção Me quei - ra me dar ben - ção $\quad$ Mi - nha

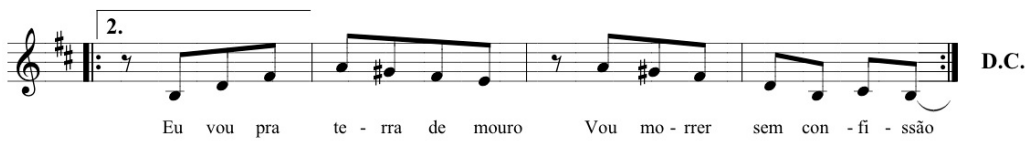

Figura 6: Toada do boi-bumbá Pae do Campo, gravada pela Missão de Pesquisas Folclóricas em Belém do Pará, em 1938.

15 ANDRADE, Mario de. O turista aprendiz, p. 278.

16 VÁRIOS, CD The Discoteca Collection: Missão de Pesquisas Folcloricas. The Library of Congress, Rykodisc, 1997. 

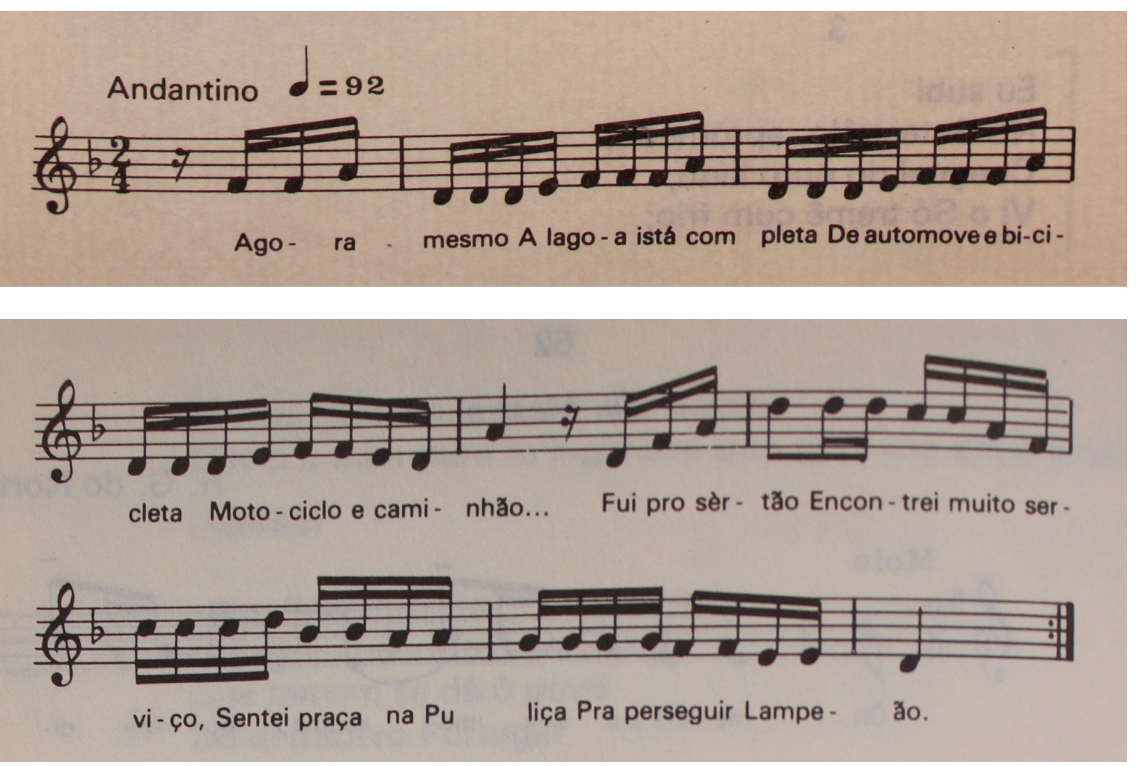

Figura 7: Páginas 113 e 114 do livro Os cocos, base para o trabalho do grupo A Barca.

Na versão d'A Barca, a melodia da segunda parte do boi foi transformada em introdução instrumental e a melodia do coco pernambucano ficou como segunda parte, permanecendo o refrão do boi como tema central. Tudo como um coco de roda, em andamento acelerado, com a temática feminina nas estrofes da segunda parte. Mais uma vez, versos de Chico Antonio e de outros cantadores presentes no livro Os cocos foram rearranjados para a construção do discurso do cantador sobre "as mulé".

\section{(Marcelo Pretto)}

a gente chega

fica logo impressionado

com o olhar enamorado

das menina do sertão

muito cuidado

por ali ninguém faz fita

cada mocinha bonita

tem um tio que é valentão

17 ANDRADE, Mário de. Os cocos, p. 113-114.

18 ANDRADE, Mário de. Os cocos p. 116.

19 ANDRADE, Mario de. Ensaio sobre a música brasileira, p. 90. 
(Juçara Marçal e Sandra Ximenez - refrão)

(Marcelo Pretto)

em riba daquela serra

tem um velho gaioleiro

quando vê moça bonita

faz gaiola sem ponteiro

naquela serra

tem três moça encantada

uma é minha, outra é tua

outra é de meu camarada

se quisé escolhe noiva

escolha pelo andá

que aquela que é veiaca

pisa no chão devagá

pra casá com moça

não case com amarela

que ela dá pra lobisome

passa a gente na moela

(Juçara Marçal e Sandra Ximenez - refrão)

(Marcelo Pretto)

homem casado

que tem amor à família

que gosta de suas filha

não devia passiá

se saí pra rua

deixa a casa em abandono

chega outro e banca dono

toma conta do lugá

mulé casada

que duvida do marido

leva a mão no pé-do-ouvido

pra deixá de duvidá

homem solteiro

namorou muié casada

tá co’a vida atrapaiada

na ponta do meu punhá 
(Juçara Marçal e Sandra Ximenez - refrão)

(Marcelo Pretto)

pois é que a vida

tá ficando muito cara

homem, agora, é coisa rara

não se pode assim achá

só macaxera

a mulher e a cachaça

num instante a gente acha

não carece procurá

cabocla Mariana

tem quatro filha solteira

tem uma cabocla mais nova

nunca vi bicha faceira

anda e remexe

quatro palmo de cadeira

premita nossa senhora

qu'essa cabocla me queira

Mário de Andrade nunca mais reencontrou Chico Antonio desde sua viagem ao Nordeste, aliás, a única vez em que esteve na região. Mas em 1943 o escritor voltaria ao cantador, transformando-o em personagem de uma série de crônicas intituladas "Vida do Cantador", ${ }^{20}$ publicadas na sua coluna "Mundo Musical", no jornal Correio da Manhã.

Chico Antonio ficaria esquecido nas páginas d'O turista aprendiz, só publicado em 1976. Mas, em 1979, o cantador é novamente localizado no Rio Grande do Norte, pelo poeta e pesquisador Deífilo Gurgel ${ }^{21}$. Essa "redescoberta" de Chico Antonio, quase octagenário, é tema do documentário Chico Antonio, o herói com caráter, de Eduardo Escorel. Em 1982, Chico Antonio grava um LP para o Instituto Nacional do Folclore/ Funarte ${ }^{22}$, acompanhado por seu vizinho Paulírio Sebastião da Silva, onde relembra uma série de cocos anotados por Mário de Andrade, como "Boi Tungão", "Adeus Luquinha da Lagoa" e "Onde Vais, Helena”. Chico

20 ANDRADE, Mário de. Vida do cantador. Edição crítica de Raimunda de Brito Batista. Belo Horizonte/Rio de Janeiro: Villa Rica, 1993.

21 Costa, Gilmara Benevides. O canto sedutor de Chico Antonio. Natal: Editora da UFRN, 2004, p. 58.

22 ANTONIO, Chico. LP No balanço do ganzá. Rio de Janeiro: Funarte, 1982. Relançado em CD pela Funarte, Coleção Itaú Cultural e Atração Fonográfica em 1998. 
Antonio falece aos 89 anos, em 1993, quando se comemora o centenário de Mário de Andrade.

Em 1998, como na ficção de Vida do cantador, Chico Antonio volta a “cantar" em São Paulo pelos músicos d’A Barca.

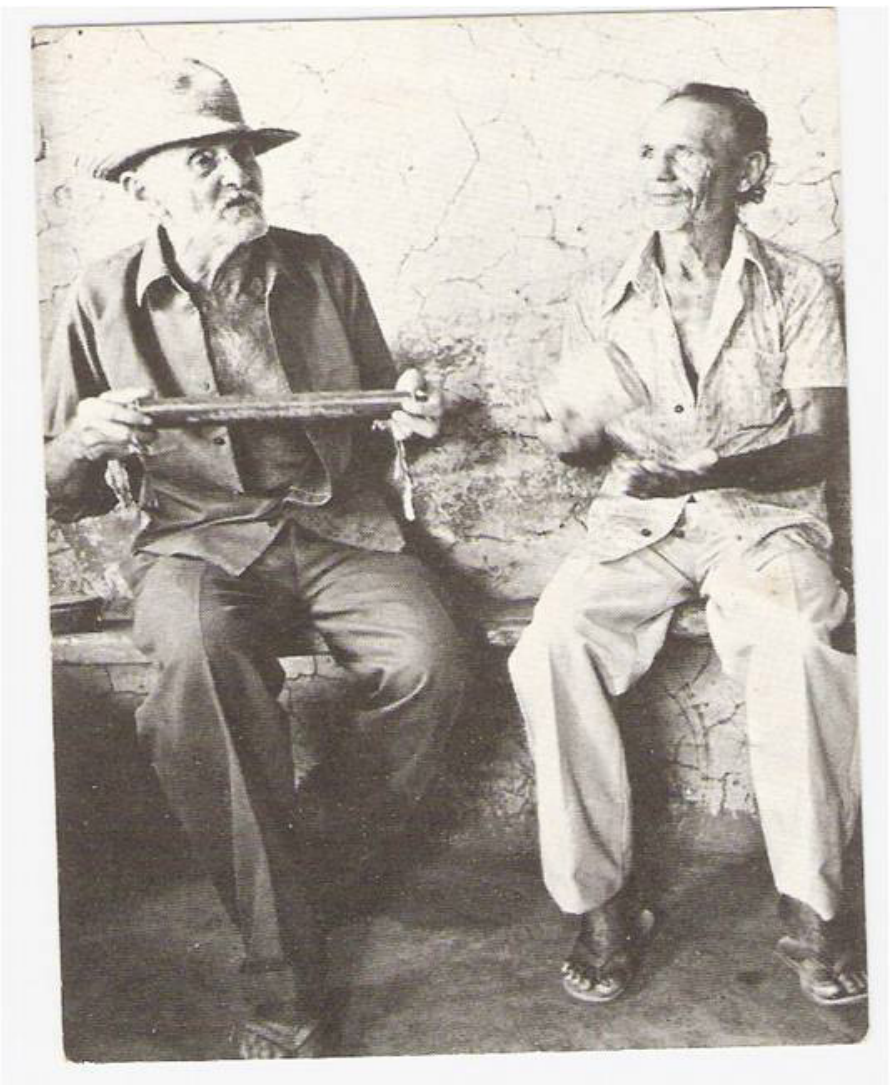

Figura 8: Chico Antonio e Paulírio Sebastião da Silva.

DOI: http://dx.doi.org/10.11606/issn.2316-901X.v0i59p419-436 
